\title{
Review
}

\section{CD44 and the ERM Family in Bone Cells}

\author{
Hiroaki Nakamura and Hidehiro Ozawa \\ First Department of Oral Anatomy, Niigata University School of Dentistry, Gakkocho-dori-2, Niigata 951
}

Received for publication March 17, 1997

We describe here the immunohistochemical localization of CD44 (hyaluronate receptor) and the ezrin-radixin-moesin (ERM) family (actin binding proteins) in bone cells and discuss possible mechanisms for the organization of their cytoskeletons.

In the cells of osteoblast-lineage, active osteoblasts showed immunoreactivity to CD44 only on their cytoplasmic processes in the bone matrix. They showed degrees of immunoreactivity to radixin and moesin on the cytoplasmic side of their basolateral plasma membrane, but not in their cytoplasmic processes. On the other hand, osteocytes demonstrated intense immunolabeling to CD44, showing scarcely any immunoreactivity to the ERM family. In osteoclasts, intense immunoreactivity to CD44 was detected on their basolateral plasma membranes. The plasma membranes of the clear zone and the ruffled border were not immuno-labeled with CD44. As for the ERM family, the basolateral plasma membrane of the osteoclasts was stained with anti-moesin monoclonal antibody, but not with anti-ezrin or anti-radixin antibody. Thirty minutes after the administration of calcitonin, osteoclasts did not show either clear zones or ruffled borders. CD44 and moesin were colocalized all along their plasma membranes, including the region facing the bone surface.

These findings suggest that: 1 ) the CD44moesin-actin filament system is involved in the cytoskeletal organization of osteoclasts and their cell-polarity; and 2) other mechanisms, rather than the CD44 and the ERM family, may be involved in the cells of osteoblast-lineage.

Key words: Osteoblasts, Osteoclasts, CD44, ERM family, Immunohistochemistry

\section{Introduction}

CD44 is expressed in a wide variety of tissue. This molecule is thought to function as a hyaluronate receptor $[19,62]$ because it demonstrates homology in the extracellular domain with a cartilage link and a proteoglycan core protein [15, 52]. Now, CD44 is a multifunctional adhesion molecule, binding to type I collagen, fibronectin and serglycin [8, 30, 59]. CD44 is reportedly involved in the attachment of hematopoietic stem cells to stromal cells

Selected by "The 10th International Congress of Histochemistry and Cytochemistry" held in Kyoto, Japan on Aug. 18-23, 1996.

Correspondence to: Dr. H. Nakamura, First Department of Oral Anatomy, Niigata University School of Dentistry, Gakkocho-dori-2, Niigata 951, Japan.
[40], in lymphocyte homing to Peyer's patches and to the high endothelial venules of peripheral lymph nodes [31], in cell migration [29], and in metastatic spread [18]. Moreover, CD44 has been thought to be associated with actin filaments [58] via an ankyrin-like molecule in its cytoplasmic domain [33, 34]. Recently, Tsukita et al. [60] reported that the ERM family, consisting of ezrin, radixin and moesin and belonging to the band 4.1 super family $[14,36,50,56]$, might connect CD44 with actin filament in microvilli, at cell-cell and cell-matrix adhesion sites. As a result, CD44 and the ERM family may be integral to the association of actin filaments with plasma membranes.

In bone tissue, the proliferation and the differentiation of bone cells requires cell-cell and cell-matrix interactions. Cell-cell interaction between osteoclasts' progenitor cells and stromal cells $[12,28,53,61]$ is essential 
for the differentiation and the activation of osteoclasts. Cell adhesion molecules, such as cadherins [55] and integrins [26], and their signal transduction systems are notable to cell-cell and cell-matrix interactions. Cells of osteoblast-lineage are reported to express $\mathrm{N}$-like cadherin [47], which is responsible for cell-cell adhesion, and $\beta 1$ integrins $[9,25]$, responsible for cell-matrix attachment. Conversely, osteoclasts express E-cadherin [38], $\alpha \mathrm{v} \beta 3$ [10, $35,41], \alpha 2 \beta 1$ integrin [20] and $\operatorname{CD} 44[4,24,46]$. Although pp60c-src $[5,22,51,57]$, PI3 kinase [23], and cytoskeletal proteins in osteoclasts are thought to participate in the signal transductions via adhesion molecules, the details of the mechanisms have not been clarified. Therefore, it behooves to investigate the localization of adhesion molecules and signaling molecules to clarify the mechanism of cell-cell and/or cell-matrix interactions in bone cells.

In the present paper, we describe the localization of CD44 and the ERM family in bone cells of mouse tibiae to clarify their roles in the organization of cytoskeletons.

\section{CD44 and the ERM family in cells of the osteoblast lineage}

Osteoblasts are thought to originate from undifferentiated mesenchymal cells. They synthesized bone matrix proteins, such as type I collagen, osteocalcin, and osteopontin according to their differentiation. Osteoblasts also express alkaline phosphatase (ALPase) on their plasma membranes and then become ALPasenegative osteocytes in the bone matrix. We observed osteoblasts and were actively forming bone matrix hardly showed immunoreactivity to CD44 on their plasma membranes, except for cytoplasmic processes in osteoid regions. However, immunoreactivity could be detected on all parts of the plasma membrane of osteocytes when osteoblasts began to be embedded in the bone matrix (Fig. 1a). The pattern of localization of CD44 is inverse to that of ALPase. CD44 is one of the useful markers for osteocytes, just as ALPase is for osteoblasts. The cytoplasmic processes of osteoblasts and
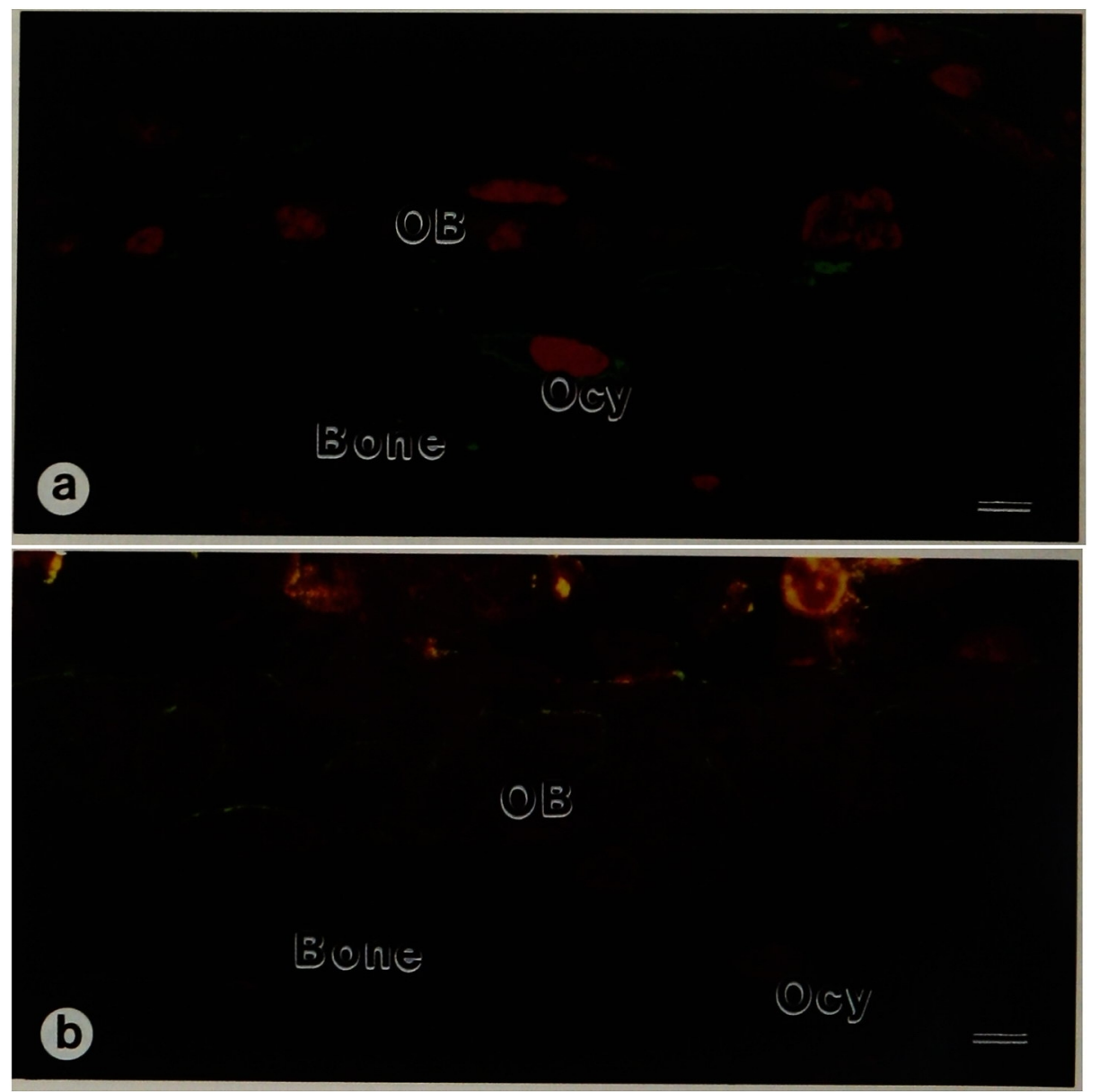

Fig. 1. Confocal laser scanning micrographs indicating the localization of CD44 and the ERM family. a: Immunoreactivity is detected in the cells of the osteoblast lineage. Intense immunoreactivity is seen on osteocytes (Ocy). However, osteoblasts (OB) on the bone surface show no immunoreactivity except to their cytoplasmic processes. b: Immunolocalization of radixin in the cells of osteoblast lineage. Osteoblasts $(\mathrm{OB})$ show immunoreactivity to radixin along their plasma membranes. However, osteocytes and their cytoplasmic processes in the bone matrices do not show any reactivity to the ERM family. Bone: bone matrix. Original magnification $=\times 600$. Bars $=10 \mu \mathrm{m}$. 
osteocytes have been shown to contain well-developed actin filaments. Chondroitin sulfate chains in CD44 may be involved in the binding of CD44 to collagen fibrils and fibronectin by their negative charge $[8,13$, 30]. CD44-positive cytoplasmic processes of osteoblasts lie parallel with collagen fibrils in osteoid regions. Therefore, CD44 on cytoplasmic processes plays an important role in the organization of collagen fibrils in bone matrix. Since no localization of the ERM family was seen in osteocytes and their cytoplasmic processes
[45], in spite of the presence of CD44 and actin filaments, we assumed that other actin-binding molecules may be responsible for regulating the organization of actin filaments in osteocytes. In contrast, immunoreactivity to radixin and moesin was detected along the plasma membrane of osteoblasts where they came into contact with each other or with bone matrices (Fig. 1b). Localization of radixin and moesin, found in the regions in contact with osteoblasts, suggests that they may be involved in cell-cell recognition and/or attachment of osteoblasts themselves.
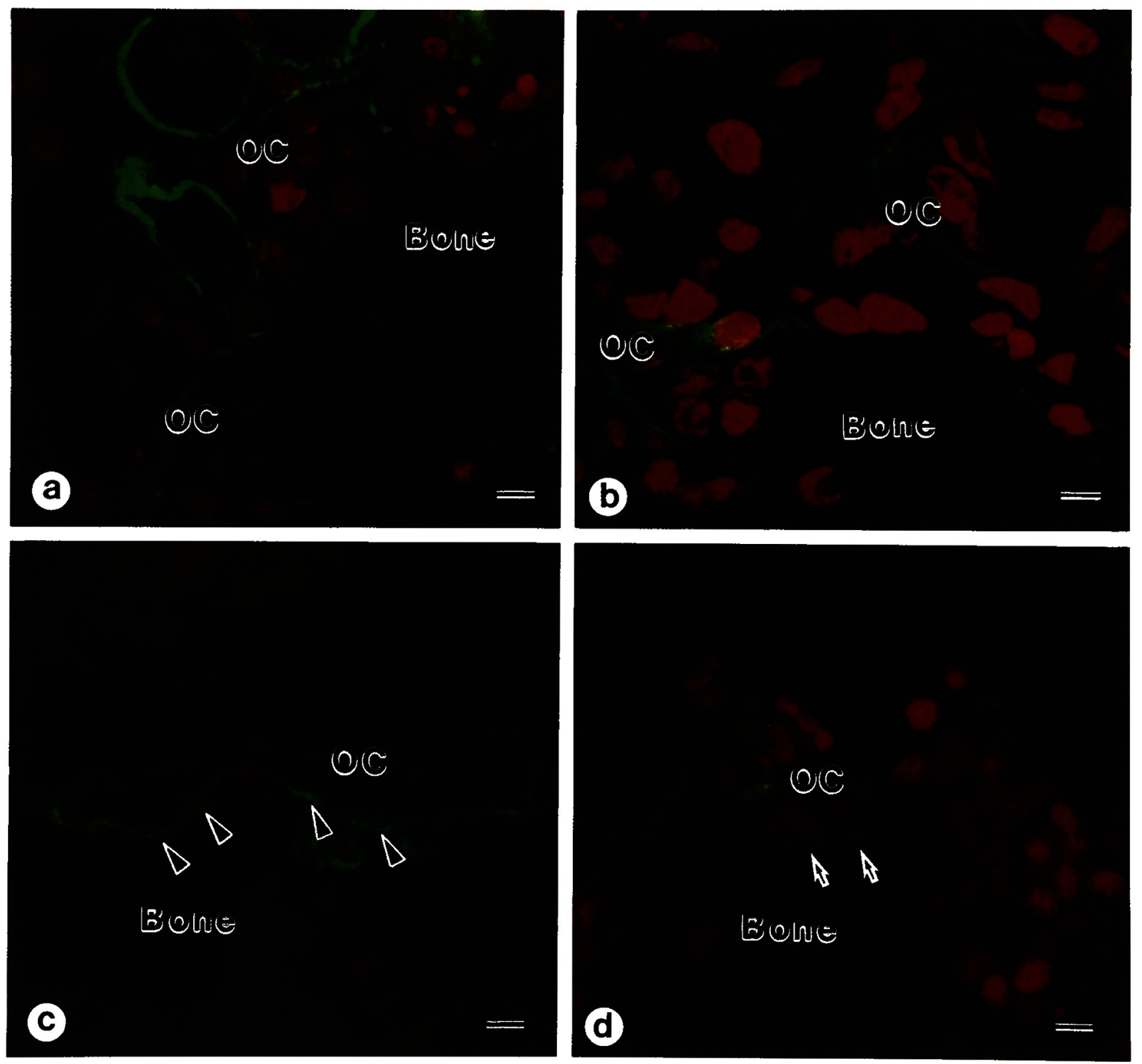

Fig. 2. Immunolocalization of CD44 and moesin on untreated osteoclasts (a, b) and calcitonin-injected osteoclasts (c, d). a: In untreated mice, osteoclast (OC) shows immunoreactivity to CD44 on the basolateral plasma membrane. b: Immunoreactivity of moesin is mainly detected on the basolateral plasma membrane of osteoclast (OC). c: Thirty minutes after the calcitonin injection, immunoreactivity to CD44 is also detected on the region (arrowheads) facing to bone surface. d: Immunoreactivity to moesin is also detected on the region (arrows) where osteoclast $(\mathrm{OC})$ comes in contact with bone surface. Bone: bone matrix. Original magnification $=\times 600$. Bars $=10 \mu \mathrm{m}$. 
However, CD44 is not localized in these regions. Other adhesion molecules may also be associated with the ERM family.

\section{CD44 and the ERM family in osteoclasts}

Osteoclasts have distinct cell-polarity and their plasma membrane is generally divided into the regions: basolateral side, clear zone and ruffled border. Bone resorption is initiated by the cell-matrix recognition between osteoclasts and the bone matrix. However, the mechanism of how osteoclasts and/or preosteoclasts recognize the bone matrix remains to be clarified. CD44 was mainly detected on the basolateral membrane of osteoclasts, surrounded by stromal cells and/or osteoblastic cells (Fig. 2a). Positive reactivity was conspicuously absent over most of the ruffled border and the clear zone. However, detached osteoclasts showed immunoreactivity along all parts of the plasma membrane. These results indicate that the localization of CD44 corresponds to the cell-polarity of osteoclasts. As for the
ERM family, osteoclasts showed immunoreactivity to moesin (Fig. 2b), but not to ezrin nor radixin [45]. Although the cytoplasm of osteoclasts also showed a weak reactivity to moesin, the stainability was intense along their basolateral plasma membrane. The immunoreactive pattern of moesin on the basolateral plasma membrane of osteoclasts resembles that of CD44. By using an electron microscopy, we noticed that CD44 was localized on the microvilli, which has well-developed networks of actin filaments, in the basolateral membrane of osteoclasts. Moesin is specifically localized beneath the plasma membrane of the microvilli. The colocalization of CD44 with moesin leads us to consider that the CD44-moesin-actin filament system is involved in the cytoskeletal organization of osteoclasts and their cell-polarity.

In order to clarify the function of this system, we investigated the change of immunolocalization of CD44 and moesin after calcitonin injection. Calcitonin directly affects the cell-polarity of osteoclasts and inhibits their bone resorbing activity $[27,32,37]$. The colocalization of CD44 and moesin was also observed on the microvillus pro-
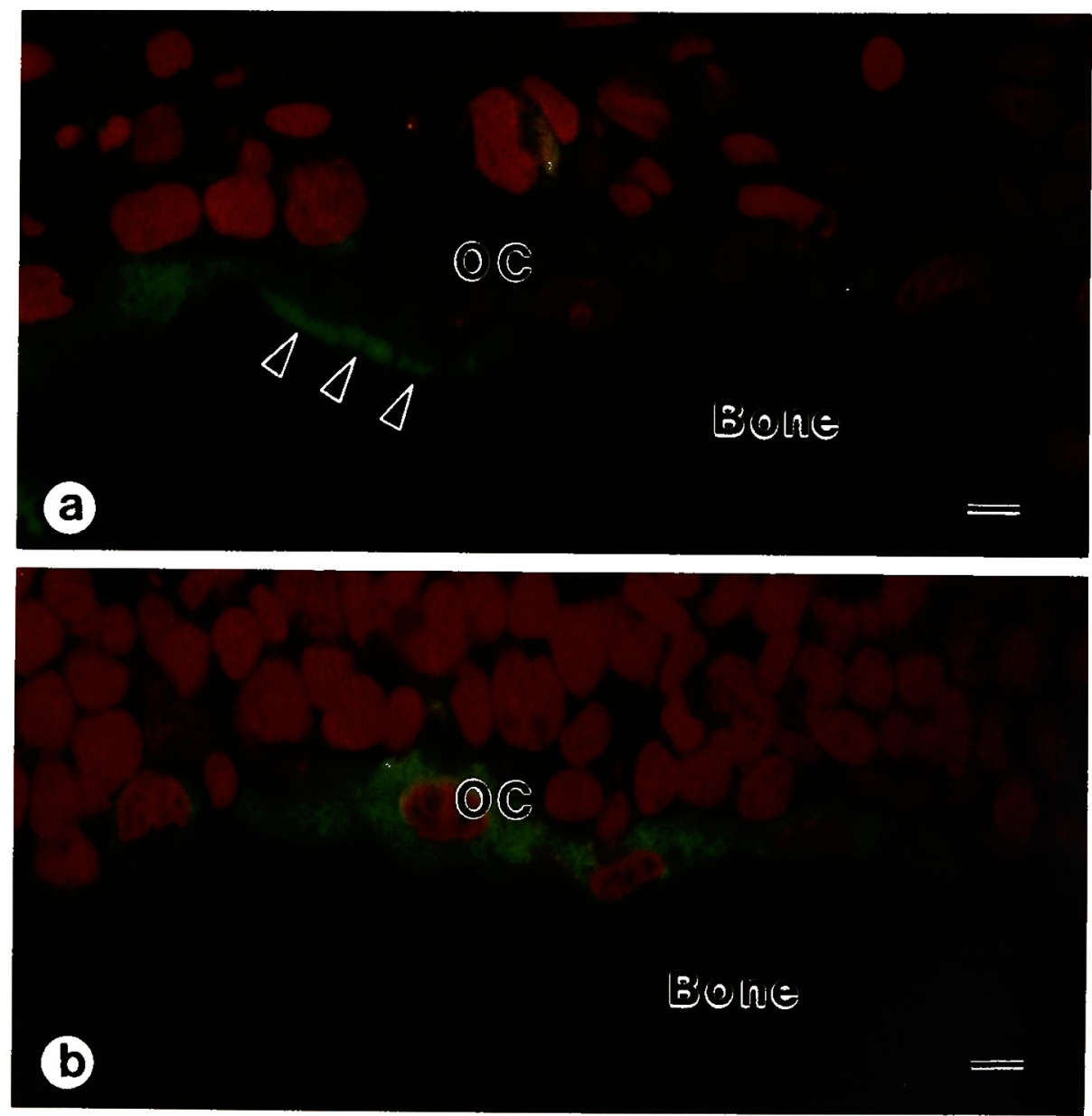

Fig. 3. Immunolocalization of $\mathbf{H}^{+}$-ATPase in osteoclasts. a: In untreated mice, osteoclast (OC) shows intense reactivity on the contacting region to the bone surface (arrowheads). b: Fifteen minutes after the calcitonin injection, immunoreactivity is seen diffusely in the cytoplasm of osteoclast $(\mathrm{OC})$. Bone: bone matrix. Original magnification $=\times 600$. Bar $=10 \mu \mathrm{m}$. 


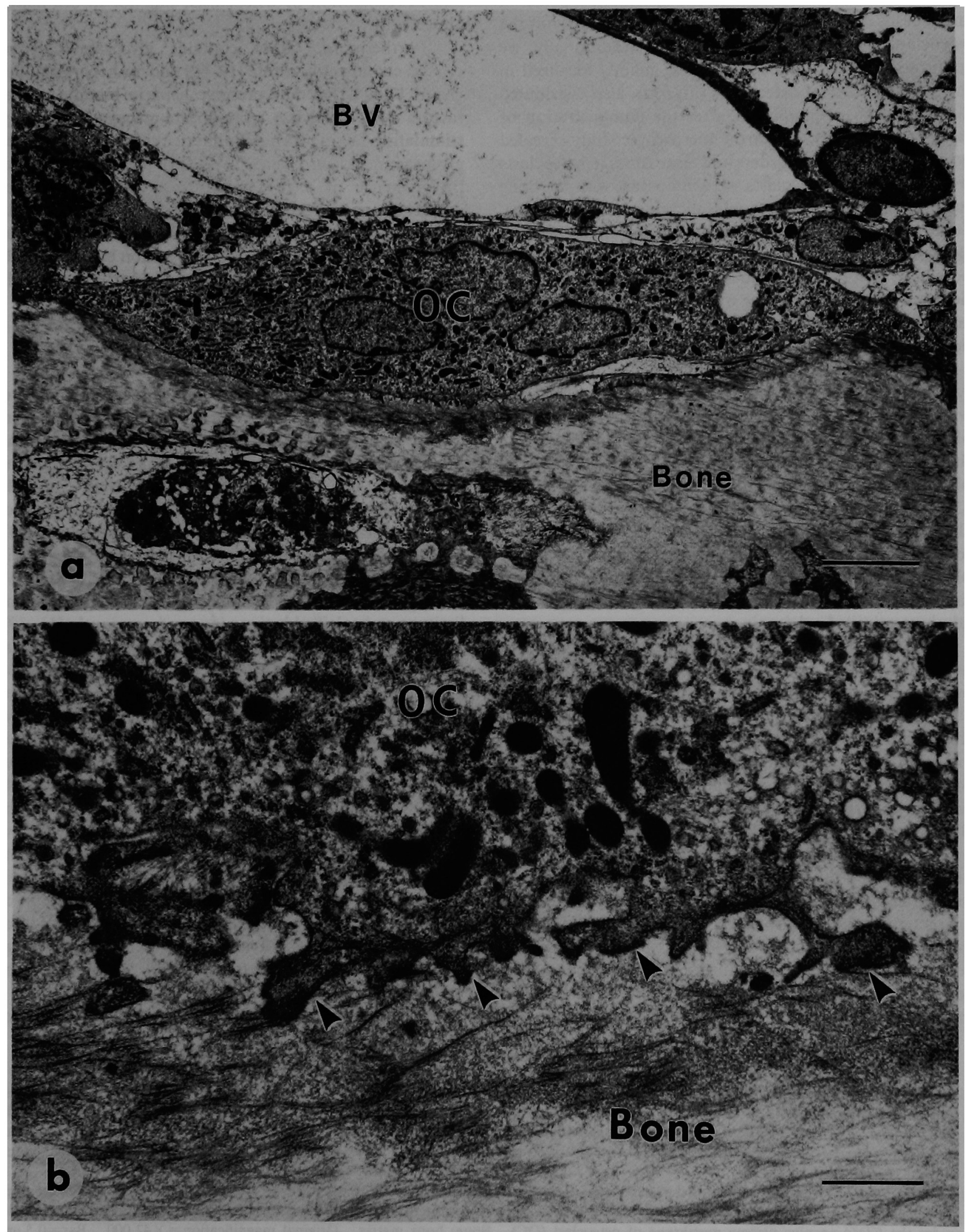

Fig. 4 
cesses facing the bone surface as well as on the basolateral plasma membrane. Changes in the distribution of CD44 and moesin corresponded to the loss of cell-polarity of the osteoclasts by calcitonin (Fig. 2-c, d). Additionally, we confirmed that vacuolar $\mathrm{H}^{+}$-ATPase, mainly localized in the ruffled border of osteoclasts (Fig. 3a), also distributed diffusely in their cytoplasms after the administration of calcitonin (Fig. 3b). Electron microscopic study revealed no observable ruffled borders and clear zones in osteoclasts (Fig. 4a). Most osteoclasts were in contact with the bone surface via finger-like cytoplasmic processes (Fig. 4b). Some osteoclasts showed intermediate structures between clear zones and ruffled borders. These findings raise the possibility that the CD44-moesin-actin filament system participates in the maintenance of cell polarity of osteoclasts and in cell-matrix recognition between osteoclasts and the bone matrix.

The ERM family is known to be a good substrate for tyrosine kinase $[6,17]$ and also is known for associating with Rho small GTP-binding protein [54] and phosphatidylinositol [21]. Additionally, threonine residue in the actin-binding domain of moesin in platelets could be phosphorylated by some stimuli, such as by thrombin [42, 43]. Furthermore, moesin is engaged in the dynamic change of filopodia and/or retraction fiber [1]. Taken together, this evidence leads us to consider that the phosphorylation of moesin may be related to the early and rapid morphological change of osteoclasts after the administration of calcitonin.

We hypothesize that the attachment of osteoclasts to bone surfaces and their acquisition of cell-polarity require multiple steps. The first step is the recognition of the calcified bone matrix by preosteoclasts and osteoclasts. In the second step, they attach themselves to the bone matrix via $\alpha v \beta 3[10,35,41]$ and/or $\alpha 2 \beta 1$ [20]. In the third step, they develop clear zones and ruffled borders, acquire cellpolarity and resorb bone matrix. We also propose that the domains of the osteoclast's plasma membrane should be divided into four parts: the basolateral plasma membrane, ruffled border, clear zone and microvillus processes in contacting sites. Microvillus processes show similar characteristics to the basolateral plasma membrane regarding the colocalization of CD44 and moesin. Since we could not detect their colocalization in neither the clear zone nor the ruffled border of osteoclasts, the CD44moesin-actin filament system in the microvillus structure in contact with the bone surface may be involved in cellmatrix recognition of osteoclasts, but not in cell-matrix attachment.

Furthermore, CD44 contains glycosaminoglycans such as chondroitin sulfate $[19,62]$ and/or heparan sulfate chains [7]. CD44 may preserve heparin binding growth factors [49], such as granulocyte-macrophage-colonystimulating-factor [16] and interleukin-3 [48] via their glycosaminoglycan chains. We have previously reported the existence of a few extracellular matrices between osteoclasts and stromal or osteoblastic cells [44]. Thus, CD44- and moesin-positive microvilli of osteoclasts may not only be involved in cell-cell recognition but also in cellcell interaction with osteoblastic and/or stromal cells through the extracellular matrices between them.

\section{Perspective}

The ligands of CD44 in osteoclasts and osteocytes have not been determined. Recently, Weber et al. [63] indicated that osteopontin (OPN), one of none-collagenous bone matrix proteins, is also a ligand of CD44 and causes chemotactic activity for CD44-expressed cells. In addition, its adhesive mechanism seems to be independent of the arginine-glycine-aspartic acid (RGD) sequence [63]. We also investigated the immunolocalization of OPN in the process of recovery from the effect of calcitonin. We confirmed that OPN is localized on cement lines, lamina limitans and calcified loci, as reported previously [11, 39]. Double-staining of CD44 and OPN revealed that OPN was detectable on the bone surface under the CD44-positive cytoplasmic processes of osteoclasts (Fig. 5a). However, colocalization was not always observed. OPN-negative areas were also observed under CD44-positive cytoplasmic processes. We have not been able to gain conclusive information about the cell-matrix recognition between CD44 and OPN. Further investigation is required to clarify the relationships between CD44 and OPN. Additionally, we also observed the localization of hyaluronate by using biotinylated hyaluronic acid binding region [2, 3]. Hyaluronate was localized near the basolateral region of osteoclasts (Fig. 5b), suggesting that one of ligands of CD44 in osteoclasts is hyaluronate. It remains unclear what kinds of signal transduction are caused by hyaluronate.

The evidence that the ERM family in the cells of

\footnotetext{
Fig. 4. Electron micrographs of osteoclast $30 \mathrm{~min}$ after the calcitonin injection. a: Most osteoclasts show flattened-shape. Neither the ruffled border nor the clear zone is observed in osteoclast $(O C)$. Bone: bone matrix, BV: blood vessel. Original magnification $=\times 3,500$. Bars $=5 \mu \mathrm{m}$. b: Highly magnified electron micrograph of the region where osteoclast $(O C)$ comes into contact with the bone surface. Small cytoplasmic processes (arrowheads) of osteoclast are seen on the contact site to the bone surface. Bone: bone matrix. Original magnification $=\times 18,000 . \quad B a r=1 \mu \mathrm{m}$.

Fig. 5. Electron micrographs indicating the localization of $C D 44, O P N$ and hyaluronate in osteoclast. a: Double-stained electron micrograph showing the localization of CD44 and OPN. Gold particles (arrowheads) indicating the localization of OPN are seen on the bone surface under the CD44-positive plasma membrane of osteoclast (OC). Bone: bone matrix. Original magnification $=\times 42,000$. Bar $=0.5 \mu \mathrm{m}$. b: Localization of hyarulonate by HABR method. Labeling (arrows) is seen around the basolateral plasma membrane of osteoclast (OC). Original magnification $=\times 20,000$. Bar $=1 \mu \mathrm{m}$.
} 

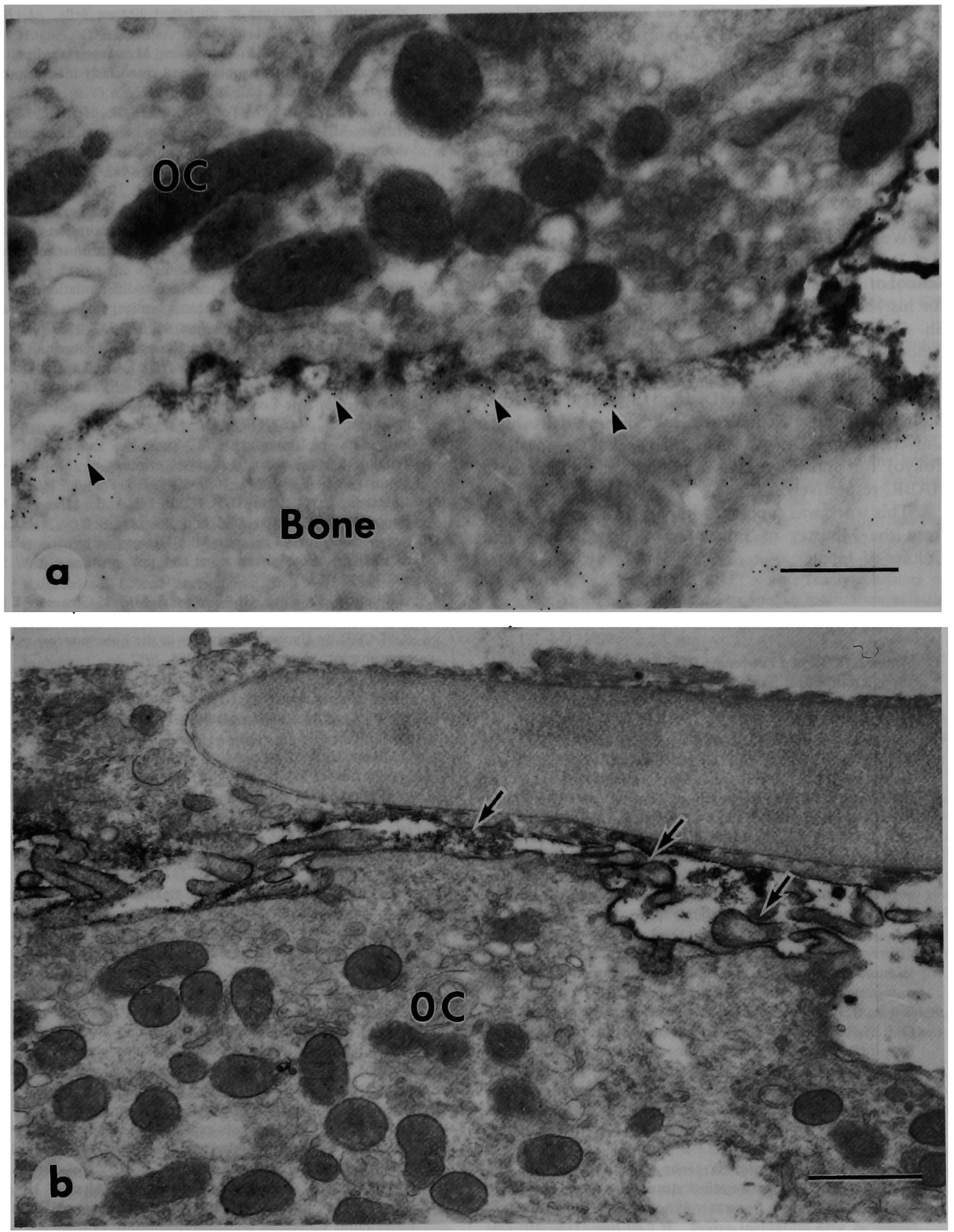

Fig. 5 
osteoblast-lineage does not colocalize with CD44 indicates that other actin-binding proteins or band 4.1 family may play a role in their cytoskeletal organization. The differential expression of the ERM family in bone cells indicates that they have distinct properties in their cytoskeletal organization. Cytoskeletal molecules associated with CD44 in osteocytes and adhesion molecules coupled with the ERM family in osteoblasts also remain to be identified.

\section{Acknowledgments}

We would like to thank all members of our laboratory (1st Department of Oral Anatomy, Niigata University School of Dentistry) for their assistance, especially S. Ejiri for his helpful discussions. We are also grateful to Dr. Sh. Tsukita (Department of Cell Biology, Graduate School of Medicine, Kyoto University) for his generous gift of anti-mouse ERM monoclonal antibodies. We thank to Dr. Y. Moriyama (Division of Marine Molecular Biology, Graduate School of Gene Sciences, Hiroshima University) and Dr. A. Asari (Seikagaku Corporation, Tokyo) for anti- $\mathrm{H}^{+}$-ATPase antibody and biotinylated HABR, respectively.

This work was supported in part by a research grant from the Ministry of Education, Science, Sports and Culture of Japan.

\section{References}

1. Amieva, M. R. and Furthmayr, H.: Subcellular localization of moesin in dynamic filopodia, retraction fibers, and other structures involved in substrate exploration, attachment, and cell-cell contacts. Exp. Cell Res. 219; 180-196, 1995.

2. Asari, A., Miyauchi, S., Miyazaki, K., Hamai, A., Horie, K., Takahashi, T., Sekiguchi, T., Machida, A., Kohno, K. and Uchiyama, Y.: Intra- and extracellular localization of hyaluronic acid and proteoglycan constituents (chondroitin sulfate, keratan sulfate, and protein core) in articular cartilage of rabbit tibia. J. Histochem. Cytochem. 40; 1693-1703, 1992.

3. Asari, A., Kuriyama, S., Kominami, E. and Uchiyama, Y.: Cytochemical localization of hyaluronic acid in human synovium with special reference of its possible process of degradation. Arch. Histol. Cytol. 58; 65-76, 1995.

4. Athanasou, N.A. and Quinn, J.: Immunophenotypic differences between osteoclasts and macrophage polykaryons: immunohistological distinction and implications for osteoclast ontogeny and function. J. Clin. Pathol. 43; 997-1003, 1990.

5. Boyce, B. F., Yoneda, Y., Lowe, C., Soriano, P. and Mundy, G. R.: Requirement of pp60 ${ }^{c-s r c}$ expression for osteoclasts to form ruffled borders and resorb bone in mice. J. Clin. Invest. 90; 1622-1627, 1992.

6. Bretscher, A.: Rapid phosphorylation and reorganization of ezrin and spectrin accompany morphological changes induced in A-432 cells by epidermal growth factor. J. Cell Biol. 108; 921-930, 1989.

7. Brown, T. A., Bouchard, T., John, T.S., Wayner, E. and Carter, W. G.: Human keratinocytes express a new CD44 core protein (CD44E) as a heparan-sulfate intrinsic membrane proteoglycan with additional exons. J. Cell Biol. 113; 207-221, 1991.

8. Carter, W. G. and Wayner, E. A.: Characterization of the class III collagen receptor, a phosphorylated, transmembrane glycoprotein expressed in nucleated human cells. J. Biol. Chem. 263; 4193-4201, 1988.

9. Clover, J., Dodds, R. A. and Gowen, M.: Integrin subunit expression by human osteoblasts and osteoclasts in situ and in culture. J. Cell Sci. 103; 267-271, 1992.

10. Davies, J., Warwick, J., Totty, N., Philp, R., Helfrich, M. and Horton, M.: The osteoclast functional antigen, implicated in the regulation of bone resorption, is biochemically related to the vitronectin receptor. J. Cell Biol. 109; 1817-1826, 1989.

11. Dodds, R. A., Connor, J. R., James, I. E., Rykaczewski, E. L., Appelbaum, E., Dul, E. and Gowen, M.: Human osteoclasts, not osteoblasts, deposit osteopontin onto resorption surfaces: an in vitro and ex vivo study of remodeling bone. J. Bone Miner. Res. 10; 1666-1680, 1995.

12. Ejiri, S.: The preosteoclast and its cytodifferentiation into the osteoclast: ultrastructural and histochemical studies of rat fetal parietal bone. Arch. Histol. Jpn. 46; 533-557, 1983.

13. Faassen, A. E., Schrager, J. A., Klein, D. J., Oegema, T. R., Couchman, J. R. and McCarthy, J. B.: A cell surface chondroitin sulfate proteoglycan, immunologically related to CD44, is involved in type I collagen-mediated melanoma cell motility and invasion. J. Cell Biol. 116; 521-531, 1992.

14. Funayama, N., Nagafuchi, A., Sato, N., Tsukita, Sa. and Tsukita, Sh.: Radixin is a novel member of the band 4.1 family. J. Cell Biol. 115; 1039-1048, 1991.

15. Goldstein, L. A., Zhou, D. F. H., Picker, L. J., Minty, C. N., Bargatze, R. F., Ding, J.F. and Butcher, E. C.: A human lymphocyte homing receptor, the Hermes antigen, is related to cartilage proteoglycan core and link proteins. Cell 56; 1063-1072, 1989.

16. Gordon, M. Y., Riley, G. P., Watt, S. M. and Greaves, M. F.: Compartmentalization of a haematopoietic growth factor (GM-CSF) by glycosaminoglycans in the bone marrow microenvironment. Nature 326; 403-405, 1987.

17. Gould, K. L., Bretscher, A., Esch, F. S. and Hunter, T.: cDNA cloning and sequencing of the protein-tyrosine kinase substrate, ezrin, reveals homology to band 4.1. EMBO J. 8; 4133-4142, 1989.

18. Günthert, U., Hofmann, M., Rudy, W., Reber, S., Zöller, M., Haußmann, I., Ponta, H. and Herrlich, P.: A new variant of glycoprotein CD44 confers metastatic potential to rat carcinoma cells. Cell 65; 13-24, 1991.

19. Haynes, B. F., Liao, H.X. and Patton, K. L.: The transmembrane hyaluronate receptor (CD44): multiple functions, multiple forms. Cancer Cells 3; 347-350, 1991.

20. Helfrich, M. H., Nesbitt, S. A., Lakkakorpi, P. T., Barnes, M. J., Bodary, S. C., Shankar, G., Mason, W. T., Mendrick, D. L., Väänänen, H.K. and Horton, M. A.: $\beta 1$ integrins and osteoclast function: involvement in collagen recognition and bone resorption. Bone 19; 317-328, 1996.

21. Hirao, M., Sato, N., Kondo, T., Yonemura, S., Monden, M. Sasaki, T., Takai, Y., Tsukita, Sh. and Tsukita, Sa.: Regulation mechanism of ERM (ezrin/radixin/moesin) protein/ plasma membrane association: Possible involvement of phosphatidylinositol turnover and Rho-dependent signaling pathway. J. Cell Biol. 135; 37-51, 1996.

22. Horne, W. C., Neff, L., Chatterjee, D., Lomri, A., Levy, J. B. and Baron, R.: Osteoclasts express high levels of pp60-ssc in association with intracellular membranes. J. Cell Biol. 119; 1003-1013, 1992.

23. Hruska, K. A., Rolnick, F., Huskey, M., Alvarez, U. and Cheresh, D.: Engagement of the osteoclast integrin $\alpha v \beta 3$ by osteopontin stimulates phosphatidylinositol 3-hydroxyl kinase activity. Endocrinology 136; 2984-2992, 1995.

24. Hughes, D. E., Salter, D. M. and Simpson, R.: CD44 expres- 
sion in human bone: a novel marker of osteocytic differentiation. J. Bone Miner. Res. 9; 39-44, 1994.

25. Hughes, D. E., Salter, D. M., Dedhar, S. and Simpson, R.: Integrin expression in human bone. J. Bone Miner. Res. 8; 527-533, 1993.

26. Hynes, R. O.: Integrins: a family of cell surface receptors. Cell 48; 549-554, 1987.

27. Ikegame, M., Ejiri, S. and Ozawa, H.: Histochemical and autoradiographic studies on elcatonin internalization and intracellular movement in osteoclasts. J. Bone Miner. Res. 9; 25-37, 1994.

28. Irie, K. and Ozawa, H.: Relationships between tooth eruption, occlusion and alveolar bone resorption: cytological and cytochemical studies of bone resorption on rat incisor alveolar bone facing the enamel. Arch. Histol. Cytol. 53; 497-509, 1990.

29. Jacobson, K., O'dell, D., Holifield, B., Murphy, T. L. and August, J. T.: Redistribution of a major cell surface glycoprotein during cell movement. J. Cell Biol. 99; 1613-1623, 1984.

30. Jalkanen, S. and Jalkanen, M.: Lymphocyte CD44 binds the COOH-terminal heparin-binding domain of fibronectin. $J$. Cell Biol. 116; 817-825, 1992.

31. Jalkanen, S., Bargatze, R.F., Toyos, J. and Butcher, E. C.: Lymphocyte recognition of high endothelium: antibodies to distinct epitopes of an 85-95 kD glycoprotein antigen differentially inhibit lymphocyte binding to lymph node, mucosal, or synovial endothelial cells. J. Cell Biol. 105; 983-990, 1987.

32. Kallio, D. M., Garant, P. R. and Minkin, C.: Ultrastructural effects of calcitonin on osteoclasts in tissue culture. $J$. Ultrastruc. Res. 39; 205-216, 1972.

33. Kalomiris, E. L. and Bourguignon, L. Y. W.: Mouse T lymphoma cells contain a transmembrane glycoprotein (GP85) that binds ankyrin. J. Cell Biol. 106; 319-327,1988.

34. Lacy, B. E. and Underhill, C. B.: The hyaluronate receptor is associated with actin filaments. J. Cell Biol. 105; 1395-1404, 1987.

35. Lakkakorpi, P. T., Horton, M. A., Helfrich, M. H., Karhukorpi, E.-K. and Väänänen, H.K.: Vitronectin receptor has a role in bone resorption but does not mediate tight sealing zone attachment of osteoclasts to the bone surface. J. Cell Biol. 115; 1179-1186, 1991.

36. Lankes, W. T. and Furthmayr, H.: Moesin: a member of the protein 4.1-talin-ezrin family of proteins. Proc. Natl. Acad. Sci. U.S.A. 88; 8297-8301, 1991.

37. Lucht, U.: Effects of calcitonin on osteoclasts in vivo. An ultrastructural and histochemical study. Z. Zellforsch. Mikrosk. Anat. 145; 75-87, 1973.

38. Mbalaviele, G., Chen, H., Boyce, B. F., Mundy, G. R. and Yoneda, Y.: The role of cadherin in the generation of multinucleated osteoclasts from mononuclear precursors in murine marrow. J. Clin. Invest. 95; 2757-2765, 1995.

39. McKee, M. D., Farach, C. M., Butler, W. T., Hauschka, P. V. and Nanci, A.: Ultrastructural immunolocalization of noncollagenous (osteopontin and osteocalcin) and plasma (albumin and alpha 2HS-glycoprotein) proteins in rat bone. J. Bone Miner. Res. 8; 485-496, 1993.

40. Miyake, K., Medina, K. L., Hayashi, S., Ono, S., Hamaoka, T. and Kincade, P. W.: Monoclonal antibodies to Pgp-1/ CD44 block lympho-hemopoiesis in long-term bone marrow cultures. J. Exp. Med. 171; 477-488, 1990.

41. Miyauchi, A., Alvarez, J., Greenfield, E. M., Teti, A., Grano, M., Colucci, S., Zambonin-Zallone, A., Ross, F. P., Teitelbaum, S. L., Cheresh, D. and Hruska, K. A.: Recognition of osteopontin and related peptides by an $\alpha \mathrm{V} \beta 3$ integrin stimulates immediate cell signals in osteoclasts. J. Biol. Chem. 266; 20369-20374, 1991.
42. Nakamura, F., Amieva, M. R. and Furthmayr, H.: Phosphorylation of threonine 558 in the carboxyl-terminal actin-binding domain of moesin by thrombin activation of human platelets. J. Biol. Chem. 270; 31377-31385, 1995.

43. Nakamura, F., Amieva, M. R., Hirota, C., Mizuno, Y. and Furthmayr, H.: Phosphorylation of ${ }^{88} \mathrm{~T}$ of moesin detected by site-specific antibodies in RAW264.7 macrophages. Biochem. Biophys. Res. Comm. 226; 650-656, 1996.

44. Nakamura, H. and Ozawa, H.: Immunohistochemical localization of heparan sulfate proteoglycan in rat tibiae. J. Bone Miner. Res. 9; 1289-1299, 1994.

45. Nakamura, H. and Ozawa, H.: Immunolocalization of CD44 and ERM family in osteoblasts and osteoclasts in mouse tibiae. J. Bone Miner. Res. 11; 1715-1722, 1996.

46. Nakamura, H., Kenmotsu, S., Sakai, H. and Ozawa, H.: Localization of CD44, the hyaluronate receptor, on the plasma membrane of osteocytes and osteoclasts in rat tibiae. Cell Tissue Res. 280; 225-233, 1995.

47. Okazaki, M., Takeshita, S., Kawai, S., Kikuno, R., Tsujimura, A., Kudo, A. and Amann, E.: Molecular cloning and characterization of OB-cadherin, a new member of cadherin family expressed in osteoblasts. J. Biol. Chem. 269; 1209212098, 1994.

48. Roberts, R., Gallagher, J., Spooncer, E., Allen. T, D., Bloomfield, F. and Dexter, T.M.: Heparan sulfate bound growth factors: a mechanism for stromal cell mediated haemopoiesis. Nature 332; 376-378, 1988.

49. Ruoslahti, E. and Yamaguchi, Y.: Proteoglycans as modulators of growth factor activities. Cell 64; 867-869, 1991.

50. Sato, N., Funayama, N., Nagafuchi, A., Yonemura, S., Tsukita, Sa. and Tsukita, Sh.: A gene family consisting of ezrin, radixin, and moesin. Its specific localization at actin filament/plasma membrane association sites. J. Cell Sci. 103; 131-143, 1992.

51. Soriano, P., Montgomery, C., Geske, R. and Bradley, A.: Targeted disruption of the c-src proto-oncogene leads to osteopetrosis in mice. Cell 64; 693-702,1991.

52. Stamenkovic, I., Amiot, M., Pesando, J. M. and Seed, B.: A lymphocyte molecule implicated in lymph node homing is a member of the cartilage link protein family. Cell 56; 1057$1062,1989$.

53. Takahashi, N., Akatsu, T., Udagawa, N., Sasaki, T., Yamaguchi, A., Moseley, J. M., Martin, T. J. and Suda, T.: Osteoblastic cells are involved in osteoclast formation. Endocrinology 123; 2600-2602, 1988.

54. Takaishi, K., Sasaki, T., Kameyama, T., Tsukita, Sa., Tsukita, Sh. and Takai, Y.: Translocation of activated Rho from the cytoplasm to membrane ruffling area, cell-cell adhesion sites and cleavage furrows. Oncogene 11; 39-48, 1995.

55. Takeichi, M.: The cadherins: cell-cell adhesion molecules controlling animal morphogenesis. Development 102; 639-655, 1988.

56. Takeuchi, K., Kawashima, A., Nagafuchi, A. and Tsukita, Sh.: Structural diversity of band 4.1 superfamily members. J. Cell Sci. 107; 1921-1928, 1994.

57. Tanaka, S., Takahashi, N., Udagawa, N., Sasaki, T., Fukui, Y., Kurokawa, T. and Suda, T.: Osteoclasts express high levels of pp60-src, preferentially on ruffled border membranes. FEBS letters 313; 85-89, 1992.

58. Tarone, G., Ferracini, R., Galetto, G. and Comoglio, P.: A cell surface integral membrane glycoprotein of $85,000 \mathrm{~mol} w \mathrm{wt}$ (gp85) associated with Triton X-100-insoluble cell skeleton. J. Cell Biol. 99; 512-519, 1984.

59. Toyama-Sorimachi, N., Sorimachi, H., Tobita, Y., Kitamura, F., Yagita, H., Suzuki, K. and Miyasaka, M.: A novel ligand for CD44 is serglycin, a hematopoietic cell lineage-specific 
proteoglycan. J. Biol. Chem. 270; 7437-7444, 1995.

60. Tsukita, Sa., Oishi, K., Sato, N., Sagara, J., Kawai, A. and Tsukita, Sh.: ERM family members as molecular linkers between the cell surface glycoprotein CD44 and actin-based cytoskeletons. J. Cell Biol. 126; 391-401, 1994.

61. Udagawa, N., Takahashi, N., Akatsu, T., Sasaki, T., Yamaguchi, A., Kodama, H., Martin, T.J. and Suda, T.: The bone marrow-derived stromal cell lines MC3T3-G2/PA6 and
ST2 support osteoclast-like cell differentiation in cocultures with mouse spleen cells. Endocrinology 125; 1805-1813, 1989.

62. Underhill, C.: CD44: the hyaluronan receptor. J. Cell Sci. 103; 293-298,1992.

63. Weber, G. F., Ashkar, S., Glimcher, M. J. and Cantor, H.: Receptor-ligand interaction between CD44 and osteopontin (Eta-1). Science 271; 509-512, 1996. 